\title{
Modelling and assessing driving factors of the spatial and temporal dynamics of the sand dunes in the district of Errachidia, Morocco
}

\author{
Tudal SINSIN ${ }^{1}$, Fouad MOUNIR ${ }^{2}$, and Ahmed El ABOUDI ${ }^{1}$ \\ ${ }^{1}$ Mohammed 5 University, Faculty of Science of Rabat \\ ${ }^{2}$ National Forestry School of Engineers, Sale, Morocco
}

May 17, 2021

\begin{abstract}
The desertification affects more than 250,000 ha in the district of Errachidia and results in the expansion of desert landscapes such as the Regs, Hamadas and the Dunes. The latter is a big concern in the district since it is the source of siltation, which threatens dwellings, cultivated lands and water bodies. It is of paramount importance to understand the causes and consequences of silting to develop strategies to combat it. Thus, first, we analysed the spatial and temporal dynamics of sand dunes until 2069 by applying the Seasonal Autoregressive Integrated Moving-Average (SARIMA) model on a time series of sand dune areas. These areas were calculated annually from 1987 to 2019 by computing the sand cover index (SCI) on Landsat satellite images. Furthermore, we evaluated the influence of different natural and human factors such as temperature, precipitation, wind, vegetation, and population growth, on sand dune dynamics using Spearman's correlation test. The results indicated that the area of sand dunes will increase by 1.7\% per year between 2019 and 2069 in the district of Errachidia. This increase would be mainly caused by the combined action of ecological factors, which vary from year to year. In general, temperature and precipitation act indirectly on wind and vegetation to influence the dynamics of sand dunes in hyper-arid areas where the soil is bare or poorly covered with vegetation, where precipitation is low and where temperature is high.
\end{abstract}

\section{Hosted file}

Main Manuscript.pdf available at https://authorea.com/users/314576/articles/445034-modellingand-assessing-driving-factors-of-the-spatial-and-temporal-dynamics-of-the-sand-dunes-inthe-district-of-errachidia-morocco 